
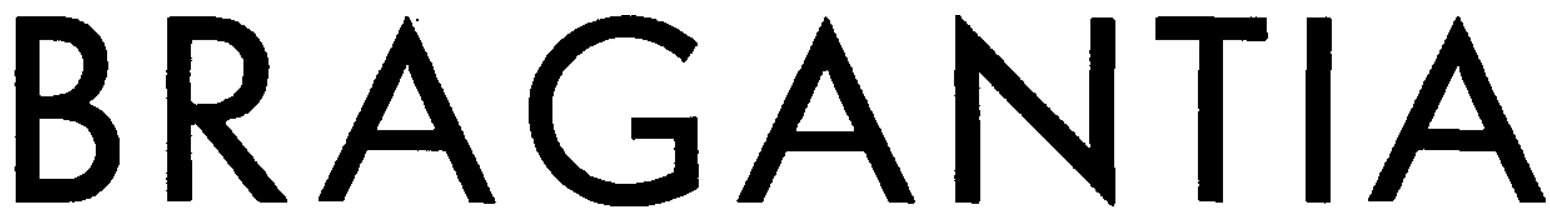

Boletim Técnico do Instituto Agronômico do Estado de São Paulo

\title{
O EMPRÊGO DE LEVEDURAS SELECIONADAS NA FERMENTAÇÃO DO VINHO (*)
}

OdetTe ZardetTo dE Toledo, engenheiro-agrônomo, Seção de Viticultura $e$ Cyro G. TẹIXEIRA, engenheiro-agrônomo, Laboratório de Microbiologia, Seção de Tecnologia Agrícola, Instituto Agronômico

\section{R E S U M O}

Ensaios foram realizados para estudar o comportamento de 25 leveduras na fermentação vinária, com o objetivo de selecionar aquelas que pudessem influir na obtenção de vinhos com grau alcoólico satisfatório e teores de ácidos voláteis e aldeído acético baixos. Os resultados obtidos mostraram que as leveduras n. 13, $14,16,25,20,15,4,3,2$ e 17 atingiram essa finalidade, podendo servir como ponto de partida para novas observaçōes nas cantinas industriais.

\section{1 - INTRODUÇÃO}

É prática comum, entre os produtores de vinho em nosso país, proceder apenas à fermentação espontânea do mosto sulfitado.

Embora a ação do metabissulfito de potássio seja a de inibir o desenvolvimento de grande parte dos microrganismos prejudiciais, encontrados naturalmente no mosto de uva, a microflora que ainda permanece ativa é bastante heterogênea e pode ser responsável pela variação de qualidade observada nos vinhos das diferentes safras. Nos anos de condições desfavoráveis, prevalecerá uma microflora com predominância de organismos indesejáveis, resultando na obtenção de vinhos inferiores.

Outro problema que se nos depara é o da variedade de uva empregada na vinificação. Nos países europeus, a predominância de viníferas constitui, só por si, uma garantia de bons vinhos. Entretanto, em nosso meio, onde as viníferas se desenvolvem mal, temos que recorrer às variedades americanas ou aos híbridos entre viníferas e americanas, cujo mosto, geralmente, apresenta qualidades inferiores àquele das viníferas. Adotar o processo de fermentação espontânea nesse mosto é acrescentar mais um fator

(*) Trabalho apresentado ao VIII Congresso Internacional de Viticultura e Enologia, realizado em Santiago do Chile, de 22 de abril a 2 de maio de 1956.

Recebido para publicação em 28 de agôsto de 1957. 
indesejável à obtenção de bons vinhos. Se a microflora dominante for pouco satisfatória, iremos fatalmente obter produto de má qualidade.

À vista do exposto, seria interessante que, ao lado de um programa de melhoramento da nossa matéria prima, isto é, da criação de novas variedades de uvas com melhores características do que as atualmente cultivadas, fôsse executado também um plano de seleção de leveduras que pudesse concorrer para melhorar o processo de vinificação.

O emprêgo de culturas de fermentos selecionados, com as características desejadas para a produção de determinado tipo de vinho, oferece uma série de vantagens largamente apontadas por diversos pesquisadores. Pelo uso destas leveduras na fermentação do mosto de uva, é possível conseguirem-se, de ano para ano, produtos mais uniformes, sendo as pequenas variações devidas à oscilação do mosto, conforme as condições climáticas que caracterizam os diversos anos, como também às variações na temperatura de fermentação, quando esta é realizada em salas onde não haja sistema de seu contrôle.

Da estirpe de levedura selecionada, utilizada na fermentação de mostos convenientemente sulfitados, vai depender, em grande parte, a composição do vinho resultante. Assim, algumas raças de leveduras vínicas produzem vinhos com maior teor alcoólico, outras produzem mais aldeídos, mais ácidos voláteis etc..

Gomes (6), estudando a microflora duriense, se refere a uma levedura que denominou Douro 72, capaz de produzir grande quantidade de ésteres a partir dos açúcares do mosto (glucose e levulose), possuindo, entretanto, diminuta capacidade de produção de álcool etílico. Nunes (8) realizou também um esbôço de estudo das leveduras vínicas portuguêsas com a finalidade de conhecer o valor enológico de cada uma delas e estabelecer policulturas a partir das leveduras que apresentassem as características desejadas na elaboração de determinado tipo de vinho.

Trabalho realizado por Gallay, Benvegnin e Capt (5), sôbre o efeito das leveduras selecionadas nos caracteres dos vinhos, levaram-nos às seguintes conclusões:

a) os vinhos obtidos a partir de mostos de igual composição, semeados com leveduras diversas, apresentam características distintas à degustação que não podem ser consideradas como obras do acaso;

b) bons resultados oriundos da utilização de culturas de fermentos selecionados, só poderão ser conseguidos por meio de uma sulfitação adequada do mosto, para evitar o desenvolvimento da flora indígena, responsável por caracteres indesejáveis; 
c) o emprêgo de leveduras selecionadas deve ser considerado como uma medida enológica indispensável, destinada, na pior das hipóteses, a evitar o retardamento da fermentação de mostos sulfitados e assegurar completa fermentação dos açúcares.

Amerine (2) também admite que o aroma desejado e o contrôle dos demais componentes dos vinhos poderão ser obtidos pelo uso de culturas mistas de fermentos selecionados. Por meio de antissépticos seletivos e de estimulantes é possível inibir o crescimento dos microrganismos indesejáveis e, ao mesmo tempo, estimular o crescimento dos desejáveis. Ter-se-ão, dêsse modo, fermentações completamente controladas.

Rankine (12) estudou o problema referente ao uso de culturas de fermentos selecionados pelos vinicultores australianos, verificando que esta prática era adotada por $75 \%$ dêsses produtores. Rankine (11) estudou também os produtos resultantes da fermentação de mosto de uva por meio de 44 estirpes de fermentos nas temperaturas de 12,25 e $35^{\circ} \mathrm{C}$, chegando às seguintes conclusões:

a) dependendo da estirpe de fermento selecionado utilizada, o teor alcoólico do mosto fermentado variou entre 8 a $15 \%$ em volume, a $25^{\circ} \mathrm{C}$;

b) a produção de álcool foi ligeiramente mais elevada nos mostos fermentados a $15^{\circ} \mathrm{C}$;

c) algumas estirpes produziram maior acidez volátil a $25^{\circ} \mathrm{C}$ do que a 15 ou $35^{\circ}$, porém, a acidez fixa e o $\mathrm{pH}$ permaneceram mais ou menos invariáveis;

d) de onze estirpes estudadas, duas produziram teor elevado de aldeído acético, particularmente a $15^{\circ} \mathrm{C}$.

Em virtude dos resultados obtidos por êsses autores, resolvemos levar avante um programa de isolamento de leveduras nativas, em diversas regiões vinícolas do Brasil, a fim de estudá-las separadamente.

Os mostos foram obtidos de uvas provindas de quatro localidades diferentes, a saber: Campinas e Jundiaí, no Estado de São Paulo, Parreiras, no Estado de Minas Gerais, e Bento Gonçalves, no Estado do Rio Grande do Sul. Dos isolamentos feitos, separamos para nossa experiência apenas as culturas de Saccharomyces, num total de 23. Para estudos comparativos, ensaiamos também duas estirpes de fermentos vínicos de procedência estrangeira.

\section{2 - MATERIAL E METODO}

Utilizamos suco de uva pasteurizado, preparado no laboratório, constituído por uma mistura de $50 \%$ de uvas da variedade Seibel 7053 e $50 \%$ Seibel 10096. O Brix do suco obtido foi $20^{\circ}$, medido a $20^{\circ} \mathrm{C}$. Adicionamos açúcar de cana a fim de elevar o Brix para um valor ao redor de $24^{\circ}$. 
Após correção do Brix, distribuímos porções de $500 \mathrm{ml}$ de suco em frascos Erlenmeyers de $1.000 \mathrm{ml}$ tamponados com algodão. A esterilização foi realizada em autoclave, com vapor fluente, durante 45 minutos. No mosto resfriado, determinou-se o teor em açúcar, acidez total e volátil, $\mathrm{pH}$ e nitrogênio. $\mathrm{O}$ teor de nitrogênio total foi de $0,096 \mathrm{~g} / 100 \mathrm{ml}$. A acidez volátil do suco esterilizado foi um tanto elevada, resultante talvez do transporte relativamente demorado, em condições de alta temperatura. $O$ pé de fermentação foi preparado em tubos de cultura, semeando-se $10 \mathrm{ml}$ de suco esterilizado com uma alça de cultura pura do fermento a ser tratado. Os fermentos submetidos a teste foram os seguintes (tratamentos):

1 - Saccharomyces cerevisiae?

Origem: híbrido Seibel 7953. Jundiaí, São Paulo.

2 - Saccharomyces oviformis

Origem: híbrido I.A.C. 74-1 (Seibel 10096 x Syrah) Campinas, São Paulo.

3 - Saccharomyces cerevisiae var. ellipsoideus

Origem: híbrido I.A.C. 74-1 (Șeibel 10096 x Syrah) Campinas, São Paulo.

4 - Saccharomyces cerevisiae var. ellipsoideus

Origem: híbrido I.A.C. 74-8 (Seibel 10096 x Syrah) Campinas, São Paulo.

5 - Saccharomyces cerevisiae var. ellipsoideus

Origem: híbrido I.A.C. 164-20 (Niágara rosada x Moscatel rosada) Campinas, São Paulo.

6 - Saccharomyces cerevisiae var. ellipsoideus

Origem: híbrido I.A.C. 116-22 (Seibel 7053 x Burgunder Kastenholtz) Campinas, São Paulo.

7 - Saccharomyces cerevisiae var. ellipsoideus

Origem: híbrido I.A.C. 116-22 (Seibel 7053 x Burgunder Kastenholtz) Campinas, São Paulo.

8 - Saccharomyces cerevisiae var. ellipsoideus

Origem: Moscatel. University of Wisconsin n. 1, U.S.A.

9 - Saccharomyces cerevisiae var. ellipsoideus

Origem: híbrido I.A.C. 124-11 (Seibel 7053 x Merlot) Campinas, São Paulo.

10 - Saccharomyces cerevisiae var. ellipsoideus

Origem: Pennsylvania State College, U.S.A.

11 - Saccharomyces cerevisiae var. ellipsoideus Origem: híbrido Seibel 7053. Jundiaí, São Paulo.

12 - Saccharomyces cerevisiae var. ellipsoideus

Origem: híbrido Seibel 10076. Campinas, São Paulo. 
13 - Saccharomyces cerevisiae var. ellipsoideus Origem: híbrido Seibel 11342. Campinas, São Paulo.

14 - Saccharomyces cerevisiae var. ellipsoideus Origem: híbrido Seibel 8745. Campinas, São Paulo.

15 - Saccharomyces cerevisiae var. ellipsoideus Origem: Pinot Chardonnay. Jundiaí, São Paulo.

16 - Saccharomyces cerevisiae var. ellipsoideus Origem: híbrido Seibel 7053. Campinas, São Paulo.

17 - Saccharomyces cerevisiae var. ellipsoideus Origem: híbrido I.A.C. 16-2 (Seibel 11342 x Moscatel de Hamburgo) Campinas, São Paulo.

18 - Saccharomyces cerevisiae var. ellipsoideus Origem: Peverella. Bento Gonçalves, Rio Grande Sul.

19 - Saccharomyces cerevisiae var. ellipsoideus Origem: Peverella. Bento Gonçalves, Rio Grande Sul.

20 - Saccharomyces chevalieri

Origem: Trebbiano. Bento Gonçalves, Rio Grande do Sul.

21 - Saccharomyces cerevisiae var. ellipsoideus Origem: híbrido Seibel 7053. Campinas, São Paulo.

22 - Saccharomyces chevalieri?

Origem: híbrido I.A.C. 74-7 (Seibel 10096 x Syrah)

Campinas, São Paulo.

23 - Saccharomyces fructuum

Origem: Semillon Jaune. Jundiaí, São Paulo.

24 - Saccharomyces cerevisiae var. ellipsoideus

Origem: mistura de variedades. Parreiras, Minas Gerais.

25 - Saccharomyces cerevisiae var. ellipsoideus

Origem: Rosati. Jundiaí, São Paulo.

A seguir colocamos os tubos já semeados em estufa a $30^{\circ} \mathrm{C}$ durante 24 horas; decorrido êsse tempo, semeamos os frascos com os $10 \mathrm{ml}$ de cultura de fermento, em câmara asséptica a fim de evitar possíveis contaminações. Uma vez semeados, foram os frascos colocados em estufa a $30^{\circ} \mathrm{C}$. Passados 40 dias procedeu-se à análise do mosto fermentado. $O$ desenvolvimento do processo fermentativo foi observado pela pesagem dos frascos em intervalos de 48 horas. No mosto fermentado determinamos o teor alcoólico, acidez total e volátil, os açúcares totais, o extrato sêco, o aldeído acético e o $\mathrm{pH}$.

A acidez total foi expressa em $\mathrm{ml}$ de $\mathrm{NaOH} 0,1 \mathrm{~N}$ necessários para titular $10 \mathrm{ml}$ de mosto fermentado, utilizando-se fenolftaleína como indicador.

As determinações de açúcares totais foram efetuadas pelo método de Eynon-Lane, de acôrdo com a técnica preconizada por Amerine (1) sendo expressos em $\mathrm{g} / 100 \mathrm{ml}$. 


\begin{tabular}{|c|c|c|c|c|c|}
\hline$\stackrel{\pi}{\Xi}$ & 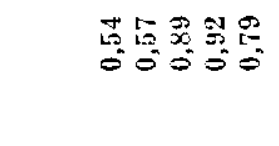 & 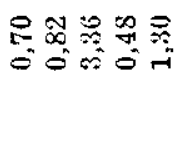 & 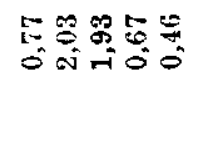 & 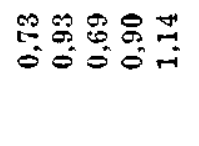 & 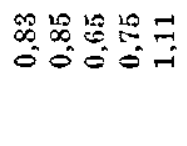 \\
\hline | & 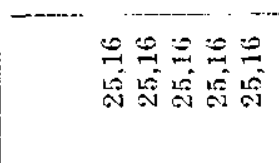 & 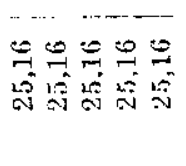 & 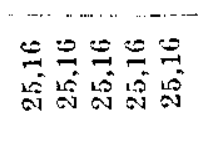 & 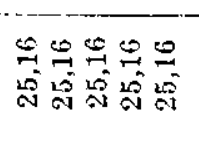 & 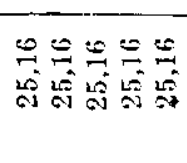 \\
\hline$\underset{\mathbb{E}}{\mathbb{E}}$ & 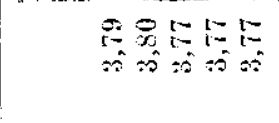 & 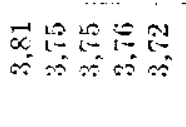 & 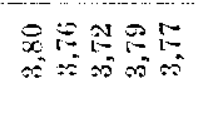 & 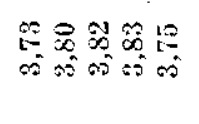 & 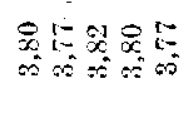 \\
\hline
\end{tabular}

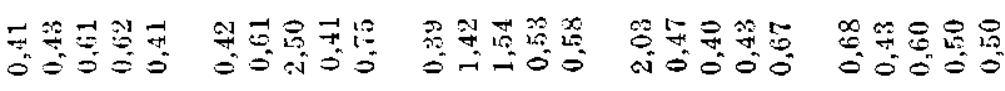

\section{$\hat{\partial} \Rightarrow$}

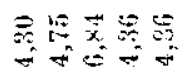

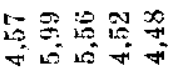

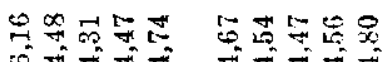

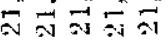

\section{$8 g 8$}

899

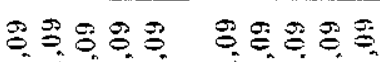

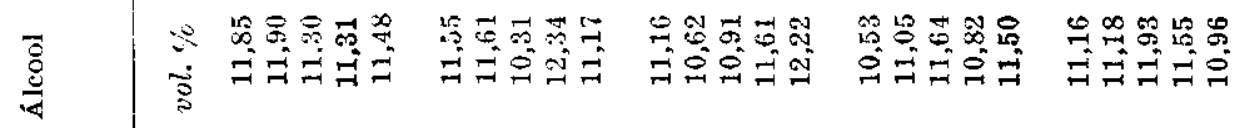

告 ح उ

\begin{tabular}{|c|c|c|c|c|}
\hline 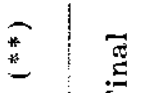 & 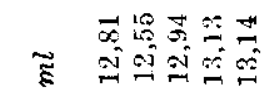 & 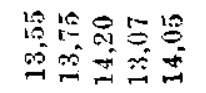 & 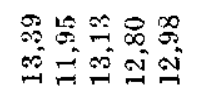 & 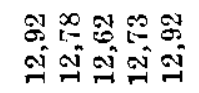 \\
\hline
\end{tabular}

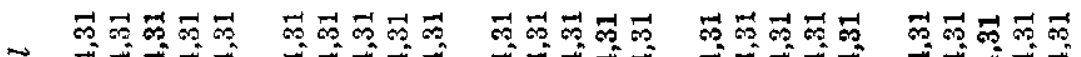

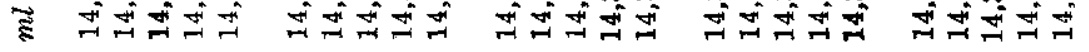

\begin{tabular}{|c|c|c|c|c|c|c|}
\hline 吾 & $\widetilde{Z}$ & 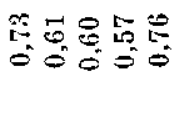 & 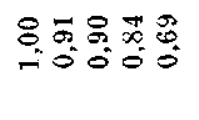 & 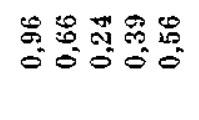 & 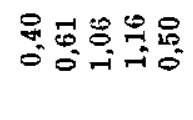 & 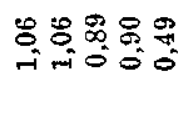 \\
\hline : & $\vec{ह}$ & 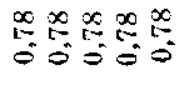 & 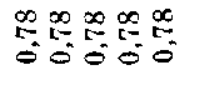 & 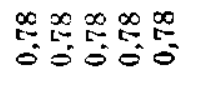 & 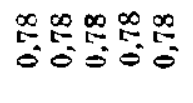 & 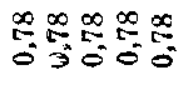 \\
\hline
\end{tabular}


O teor alcoólico foi determinado pelo refratômetro de imersão, na mistura alcoólica resultante da destilação de $100 \mathrm{ml}$ de mosto fermentado.

O extrato foi determinado pelo hidrômetro, conforme o método indicado por Amerine e Joslyn (3).

O método empregado na determinação do aldeido acético foi aquêle recomendado por Jaulmes e Espezel (7).

As experiências com as diversas leveduras consideradas foram executadas de modo a têrmos sempre seis repetições de cada um dos diferentes tratamentos.

\section{3 - APRECIAÇÃO DOS RESULTADOS}

Os resultados obtidos nas diferentes determinações estão registrados no quadro 1 .

A análise estatística demonstrou que as leveduras se comportaram diferentemente na fermentação do suco de uva. Essa análise foi feita com relação ao teor alcoólico, à acidez volátil e ao teor em aldeído acético.

As análises da variância são apresentadas a seguir.

A) análise da variância para o teor alcoólico:

\begin{tabular}{|c|c|c|c|c|}
\hline Origem da variação & $\begin{array}{l}\text { Graus de } \\
\text { liberdade }\end{array}$ & $\begin{array}{l}\text { Soma dos } \\
\text { quadrados }\end{array}$ & Variância & $\mathbf{F}$ \\
\hline Entre as estirpes . . . . . & 24 & 36,6921 & 1,5288 & 1,13 \\
\hline Nas estirpes .......... & 125 & 169,2620 & 1,3541 & $\ldots \ldots$ \\
\hline 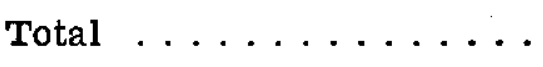 & 149 & 205,9541 & $\ldots \ldots$ & $\ldots \ldots$ \\
\hline
\end{tabular}

De acôrdo com o teste de $F$, verifica-se que não houve diferença entre as leveduras com relação ao teor alcoólico.

B) análise da variância para a acidez volátil:

\begin{tabular}{|c|c|c|c|c|}
\hline Origem da variação & $\begin{array}{l}\text { Graus de } \\
\text { liberdade }\end{array}$ & $\begin{array}{l}\text { Soma dos } \\
\text { quadrados }\end{array}$ & Variância & $\mathbf{F}$ \\
\hline Entre as estirpes $\ldots \ldots \ldots$ & 24 & 8,7235 & 0,3635 & $11,12^{* *}$ \\
\hline Nas estirpes . . . . . . . & 125 & 4,0829 & 0,0327 & $\ldots \ldots$ \\
\hline Total $\ldots \ldots \ldots \ldots$ & 149 & $\ldots \quad 12,8064$ & $\cdots \cdots$ & $\cdots \cdots \cdot$ \\
\hline
\end{tabular}


C) análise da variância para 0 aldeído acético:

\begin{tabular}{|c|c|c|c|c|}
\hline Origem da variaçāo & $\begin{array}{l}\text { Graus de } \\
\text { liberdade }\end{array}$ & $\begin{array}{l}\text { Soma dos } \\
\text { quadrados }\end{array}$ & Variância & $\mathbf{F}$ \\
\hline $\begin{array}{l}\text { Entre as estirpes } \ldots \ldots \ldots \\
\text { Nas estirpes . . . . . . . . . . . . . . . } \\
\text { Total . }\end{array}$ & $\begin{array}{r}24 \\
125 \\
149\end{array}$ & $\begin{array}{r}8.449,0707 \\
14.571,3001 \\
23.020,3708\end{array}$ & $\begin{array}{r}352,0446 \\
116,5704 \\
\ldots \ldots\end{array}$ & $\begin{array}{r}3,02^{* *} \\
\ldots \ldots \\
\ldots \ldots\end{array}$ \\
\hline
\end{tabular}

Para a acidez volátil, aplicando-se o teste de Tukey (4), foram selecionadas as seguintes leveduras, que apresentaram teores mais baixos: $n .13,14,16,25,20,15,4,3,2$ e 17, cujas diferenças das médias foram inferiores a 0,38 , ao nível de $5 \%$.

Pôde-se notar que, durante a fermentação com determinadas leveduras, ocorreu uma redução na acidez volátil, isto é, a acidez volátil final foi mais baixa do que a inicial (quadro 1).

Êsse fenômeno já tinha sido constatado por Reisch (13), que trabalhou com leveduras selecionadas em meios de culturas contendo doses crescentes de ácido acético.

Ventre (15) observou também o mesmo fenômeno quando estudava 0 efeito da adição de diferentes ácidos voláteis na fermentação do mosto de uva ou de meio sintético, esterilizados e semeados com uma cultura pura de Saccharomyces cerevisiae var. ellipsoideus. Êsse autor verificou que os ácidos voláteis experimentados desapareciam durante a marcha do processo fermentativo, dependendo da sua natureza e da sua concentração inicial a maior ou menor proporção daqueles.

Peynaud $(9,10)$ constatou que a rapidez de formação do ácido acético e queda da acidez formada variam de uma levedura para outra. Êle pôde distinguir leveduras que formam muito poucos ácidos voláteis, outras que formam relativamente bastante, e outras que provocam importantes e muito rápidas diminuições dêsses ácidos. Tais diminuições são devidas à redução do ácido acético em etanol, no curso da fermentação. Diversos observadores demonstram que o ácido acético se comporta como um aceitador de hidrogênio. Êsse pesquisador verificou que as leveduras apresentam poderes redutores diferentes e tudo se passa como se houvesse uma redução do ácido acético. A quantidade de ácido formada é função do $\mathrm{pH}$ e da raça de levedura.

Aplicando o mesmo teste de Tukey (4) para selecionar as leveduras que apresentaram menores dosagens de aldeído acético, 
obteve-se o valor de 22,85 ao nível de $5 \%$. Tôdas as leveduras estudadas não apresentaram diferenças entre as médias, com exceção da n. 8.

$\mathrm{O}$ aldeído acético é um produto intermediário na fermentação alcoólica. Trillat (14) observou que a oxidação intensa enriquece muito o vinho em aldeído. Quando o arejamento é intenso, há tendência de se formar maior quantidade de aldeído livre e o vinho adquire o odor típico de vinho arejado. Quando isso se passa com os vinhos tintos, diz-se que êle tem o gôsto de ranço. Assim, o teor em aldeído do mosto fermentado tende a aumentar nos vinhos fortemente arejados.

\section{4 - CONCLUSÕES}

Os resultados obtidos nas experiências, em escala de laboratório, levaram-nos às conclusões seguintes:

a) as leveduras estudadas comportaram-se diferentemente durante o processo de fermentação do suco de uva;

b) algumas delas resultaram na obtenção de vinhos apresentando boas características, isto é, acidez volátil reduzida e bom teor alcoólico; relativamente ao teor em aldeído acético, apenas uma demonstrou ser diferente;

c) as leveduras que mostraram ser promissoras, e que poderiam ser experimentadas em escala industrial, são as n. 13, 14, 16, $25,20,15,4,3,2$ e 17, classificadas em ordem crescente conforme o teor de ácidos voláteis;

d) o emprêgo dessas leveduras na vinificação poderia contribuir para o melhoramento das qualidades dos vinhos nacionais.

\section{THE BEHAVIOUR OF DIFFERENT YEAST STRAINS IN WINE FERMENTATION}

\section{S U M M A R Y}

Experiments were carried out on Iaboratory scale to observe the behaviour of different strains of Saccharomyces on the wine constituents. The strains of yeasts were isolated from fermented juice of various varieties of grapes raised in three different regions of Brazil. The statistical analyses of the results showed that some of the strains behaved quite differently as far as volatile acids are concerned. Some of them produce wines, with low volatile acidity looking promising to be used successfully in industrial scale as a practice to improve wine quality and acceptance.

\section{LITERATURA CITADA}

1. AMERINE, M. A. Laboratory procedures for enology. Davis, University of California, 1952. 91 p. [Mimeografado]

2. Some recent advances in enology. Wines \& Vines 34 (12) : 25-28. $1953 ; 35$ (1) : 29-30; 35 (2) : 27-30. 1954. 
3.

\& JOSLYN, M. A. Table wines. The technology of their production in California. Berkeley and Los Angeles, University of California Press, 1951. $397 \mathrm{p}$.

4. FEDERER, W. J. Experimental design. New York, The Macmillan Co., 1955. xix, 544 p. +47 p.

5. GALLAY, R., BENVEGNIN, L. \& CAPT, E. L'effect des levures sélectionnées sur les caractères du vin. Rev. rom. Agric. 8 (9):69-71. 1952.

6. GOMES, J. V. MARQUES. Microflora duriense. Primeira comunicação. Leveduras produtoras de esteres. Ann. Inst. Vinho Pôrto 2:1-20. 1945. (Separata)

7. JAULMES, P. \& ESPEZEL, P. Le dosage de l'acetaldehyde dans les vins et les spiritueux. Ann. Falsif., Paris 28:325-335. 1935.

8. NUNES, A. CAETANO. Estudos sôbre as leveduras vínicas portugueses. In Annais da Junta Nacional do Vinho. Lisboa, 1950. p. 1-14. (Separata)

9. PEYNAUD, E. Contribution a l'étude bioquimique de la maturation du raisin et de la composition des vins. Bordeaux, Faculté des Sciences, 1946. 93 p. [Tese]

10.

Sur la formation et la diminuition des acides volatils pendant la fermentation alcoolique en anaérobiose. Ann. Ferment. 5:321-337; 385-401. 1940.

11. RANKINE, B. C. Quantitative differences in products of fermentation by different strains of wine yeast. Amer. J. Enology 6 (1) :1-9. 1955.

12. Yeast cultures in Australian wine making. Amer. J. Enology 6 (3) :11-15. 1955.

13. REISCH, R. Zur Entstehung von Essigsaüre bei der alkoholischen Gärung. Zbl. Bakt. (Abt. II) 14:572-581. 1905.

14. TRILluat, A. L'aldéhyde acétique dans le vin. Ann. Inst. Pasteur 22:704, 876. 1908.

15. VENTRE, J. Acidité volatile et fermentation. Ann. Ferment. 3:447-465. 1937. 